period. Of the five patients studied one had a severe degree of haemophilia, in two it was moderate, and in two mild.

The mortality rate in the series was $20 \%$, as one patient eventually died of intracranial infection.

Carotid angiography was safely performed on seven occasions in four of the patients, human A.H.F. concentrate being used on five occasions and porcine A.H.F. concentrate on two.

It is suggested that the administration of these A.H.F. concentrates in sustained and adequate amounts to patients with classical haemophilia who are thought to be suffering from intracranial haemorrhage will possibly make it safe to use the standard techniques in establishing the precise diagnosis, and subsequently to treat a lesion by either conservative or surgical means.

We wish to thank our neurosurgical colleagues Mr. P. Harris, Mr. J. F. Shaw, and Mr. G. N. N. Reddy; and also Professor Sir
John Bruce and Dr. A. Brownlie Smith for their help with some general surgical and otorhinolaryngological aspects respectively of Case 5. We are particularly grateful to Dr. A. S. Brown, consultant anaesthetist, and Dr. A. A. Donaldson, consultant radiologist, for their skilled assistance, in particular in the performance of the percutaneous angiograms.

\section{REFERENCES}

Astrup, T. (1956). Blood, 11, 781.

Bidwell, E. (1955a). Brit. ₹. Haemat., 1, 35.

- (1955b). Ibid., 1, 386.

Biggs, R. (1957). Lancet, 2, 311.

and Douglas, A. S. (1953). F. clin. Path., 6, 23

- Eveling, J., and Richards, G. (1955). Brit. ł. Haemat., 1, 20.

and Macfarlane, R. G. (1962). Human Blood Coagulation and its Disorders, 3rd ed., p. 73 . Oxford.

Cumming, R. A., Davies, S. H., Ellis, D., and Grant, W. (1965). Vox Sang (Basel), 10, 687.

Kerr, C. B. (1964). \%. Neurol. Neurosurg. Psychiat., 27, 166.

Silverstein. A. (1960). Arch. Neurol. Psychiat. (Chic.), 3, 141.

Simpson, D. A., and Robson, H. N. (1960). Aust. N.Z.' 7. Surg., 29, 287.

\title{
Indications and Effects of Exchange Transfusion in Adults in Gynaecology and Obstetrics
}

\author{
R. H. PHILPOTT,* M.в., CH.B., M.R.C.o.g. ; N. E. G. FOSTER, $\nmid$ M.в., CH.B. \\ DERK CRICHTON, $\ddagger$ M.B., D.PHI., F.R.C.S., F.R.C.o.G.
}

Brit. med. F., 1966, 2, 1630-1633

Our findings regarding the value and safety of exchange transfusion are reported in this contribution, which follows our preliminary communication on the subject (Philpott, Foster, and Crichton, 1963). Our investigation now includes a sufficient number of cases to justify the substitution of facts for the impressions previously presented.

\section{Nature of Investigation}

This investigation, which extended from 1 November 1962 to 31 October 1963 , included all patients whose haemoglobin level was below 4.4 g. $/ 100 \mathrm{ml}$. (30\%), who did not manifest evidence of shock, and who had been admitted to the gynaecological and obstetric units at King Edward VIII Hospital, Durban.

All cases were investigated and treated by us, and an unbiased comparison of the response to exchange transfusion (group A) as opposed to slow packed-cell transfusion (group B) was undertaken. Bias in selection of either form of treatment was avoided by employing random sampling to dictate the form of treatment.

Method of Exchange Transfusion (Group A).-Blood infusion was made into a forearm vein by means of a No. 15 gauge needle. Plastic bag-containers were used for this transfusion, and a Fenwal pressure-bag was placed around the plastic bag of blood in readiness to pump the blood in under pressure. Each bag of blood was weighed and 1,250 ml. of fairly fresh blood in the form of packed cells was used. Blood removal was performed through the femoral vein by means of a bloodrecipient set and vacuum blood-bottles. The rate of withdrawal was controlled by a clamp on the plastic tubing between the

* Senior Lecturer, Head of the Sub-Department of Obstetrics, University of Natal.

† Lecturer, University of Natal.

$\ddagger$ Professor, and Head of the Division of Gynaecology and Obstetrics, University of Natal. needle and the bottle. The procedure began with the withdrawal of $200 \mathrm{ml}$. of blood from the femoral vein. Thereafter blood was pumped in as fast as possible with the Fenwal pump and blood removed at the same rate, so that at the end of the procedure $1,450 \mathrm{ml}$. of blood had been removed and $1,250 \mathrm{ml}$. of packed cells given. Great care is required to ensure that the rate of transfusion and that of removal are equated throughout, and consequently a record of the pulse, blood-pressure, and respiratory rate was kept every five minutes.

Method of Transfusing Packed Cells (Group B).-The rate of transfusion in group B was "tailored" to the clinical condition and response of the patient. Thus, if an increase occurred in the pulse rate, respiratory rate, or jugular venous pressure, then the drip rate was slowed down or stopped until the condition improved. In general the time taken for transfusing 4 units of packed cells was about three days.

Investigations.-Special investigations, undertaken in every case, included the Hess test, bleeding-time, clotting-time, a full blood count (including platelet count), fibrinogen, electrolytes and $\mathrm{CO}_{2}$-combining power, blood urea, calcium, proteins, and liver-function tests. Particular care was taken to exclude cardiac failure in every case. The tests were conducted before transfusion, and in the case of patients in group A they were repeated at 1-hour, 4-hour, and 24-hour intervals after the exchange transfusion. In group $B$ they were repeated daily for three days.

Material.-The series of 50 cases comprised every case admitted to the professorial obstetrical department and gynaecological ward. There were 25 cases in each group. The average age was 25.7 years, ranging from 21 years to 42 . The type of anaemia was diagnosed by full blood count, blood smear, and bone-marrow study. Twenty-seven cases were due to blood loss, 10 to megaloblastic anaemia, and 13 to iron deficiency. The conditions associated with the anaemia are listed in Table I. Evidence of cardiac failure was based 
primarily on elevation of the jugular venous pressure, but these patients also had other manifestations-for example, tachycardia, dyspnoea, crepitations at the lung bases, and oedema.

Apart from the foregoing detailed study our experience includes 31 subsequent exchange transfusions in patients whose clinical progress reflected, without exception, the benefits noted in the aforementioned study.

\section{TABLE I.-Clinical Diagnosis}

\begin{tabular}{|c|c|c|}
\hline & Group A & Group B \\
\hline $\begin{array}{l}\text { Following post-partum haemorrhage } \\
\text { Functional uterine bleeding } \\
\text { Post-partum megaloblastic } \\
\text { Incomplete abortion } \\
\text { Fibroids } \\
\text { Ectopic } \\
\text { Carcinoma of cervix } \\
\text { Normal pregnancy ( } 2 \text { megaloblastic, } 7 \text { Fe-deficient) } \\
\text { Obstructed labour (Fe-deficient) } \\
\text { Accidental haemorrhage (Fe-deficient) } \\
\text { Pregnancy and bleeding haemorrhoids (Fe-deficient) }\end{array}$ & $\begin{array}{l}1(1) \\
2(1) \\
3(3) \\
4(1) \\
3(1) \\
3(1) \\
0(0) \\
6(4) \\
1(1) \\
1(0) \\
1(1)\end{array}$ & $\begin{array}{l}3(0) \\
3(1) \\
5(3) \\
6(1) \\
3(1) \\
1(0) \\
1(1) \\
3(2) \\
0(0) \\
0(0) \\
0(0)\end{array}$ \\
\hline Total & $25(14)$ & $25(9)$ \\
\hline
\end{tabular}

Numbers in parentheses indicate patients in cardiac failure on admission.

\section{Results}

There were no deaths.

\section{Clinical Assessment}

Group A.-The exchange transfusion lasted 26 minutes on average, the range being 19 to 40 minutes. There was a dramatic, rapid change in the colour of the mucous membranes and skin during the exchange, and all patients remarked that they felt an improvement in their general condition. Each of the 14 patients who were in cardiac failure at the beginning of the procedure were out of failure by the end, and not a single patient had a raised jugular venous pressure after an exchange transfusion. The respiratory rate in the dyspnoeic decreased, albeit more gradually, over a four-hour period. Thus the average sespiratory rate before exchange was 29 a minute, and four hours after exchange it was 21 a minute. Typical pulse and blood-pressure changes are illustrated in the Chart, and changes in haemoglobin and packed-cell volume are reflected in Table II. The improved circulatory state following exchange transfusion made further improvement in haemoglobin level by a slow packed-cell transfusion safe where necessary. In two cases there was a marked fall in blood-pressure, and a feeble thready pulse was noted at the end of the procedure. In one of these it was due to the blood being withdrawn much faster than it had been infused; the circulatory difficulty was corrected by giving more blood. In the other it was due to blood loss from an abortion occurring during the procedure, this loss being additional to that withdrawn by the exchange transfusion. Further transfusion remedied the situation immediately.

Group B.-Nine patients were in cardiac failure on admission. In six of these recovery from failure took 48 hours on a very slow packed-cell transfusion. In the only case requiring an urgent operation (Case 24) laparotomy had to be delayed 48 hours, until the patient was out of failure and achieved a haemoglobin level of $9.4 \mathrm{~g} . / 100 \mathrm{ml}$. (64\%). Three of the patients in cardiac failure required a medical venesection while the slow packed-cell transfusion was being given. One of these cases is described as an example.

Case 34.-The patient was 20 weeks pregnant, with irondeficiency anaemia (P.C.V. 9\%, Hb 2.7 g. $/ 100 \mathrm{ml}$.) and in marked cardiac failure. She constituted a serious problem in that she became increasingly dyspnoeic soon after a very slow packed-cell transfusion was started. A medical venesection with limb cuffs eventually enabled us to give $150 \mathrm{ml}$. of packed-cell transfusion. It was not until the fourth day that she was out of cardiac failure and her haemoglobin level had risen to $8.5 \mathrm{~g} . / 100 \mathrm{ml}$.
It was found possible to give four units (approximately 270 $\mathrm{ml}$./unit) of packed cells over a period of three days to the other patients in group B. The changes in haemoglobin and packed-cell volume are reflected in Table II.

TABLE II.-Haemoglobin and P.C.V. Changes Group $A$. Exchange Transfusion

\begin{tabular}{|c|c|c|c|c|}
\hline & & Initial & 4 hrs. after E.T. & Mean increase \\
\hline $\begin{array}{l}\text { Hb (g.) } \\
\text { P.C.V. \% }\end{array}$ & $\begin{array}{l}\cdots \\
\cdots\end{array}$ & $\begin{array}{c}3 \cdot 48 \\
12 \cdot 6\end{array}$ & $\begin{array}{r}9 \cdot 7 \\
28.5\end{array}$ & $\begin{array}{r}6 \cdot 2 \\
17 \cdot 3\end{array}$ \\
\hline
\end{tabular}

Group B. 4 Units packed cells over 3 days

\begin{tabular}{ll|c|c|c}
\hline & & Initial & Day 3 & Mean increase \\
\hline Hb (g.) $\ldots$ & $\ldots$ & 3.6 & $9 \cdot 4$ & $5 \cdot 8$ \\
P.C.V. $\%$ & $\cdots$ & 12.3 & $29 \cdot 6$ & 17.3 \\
\hline
\end{tabular}

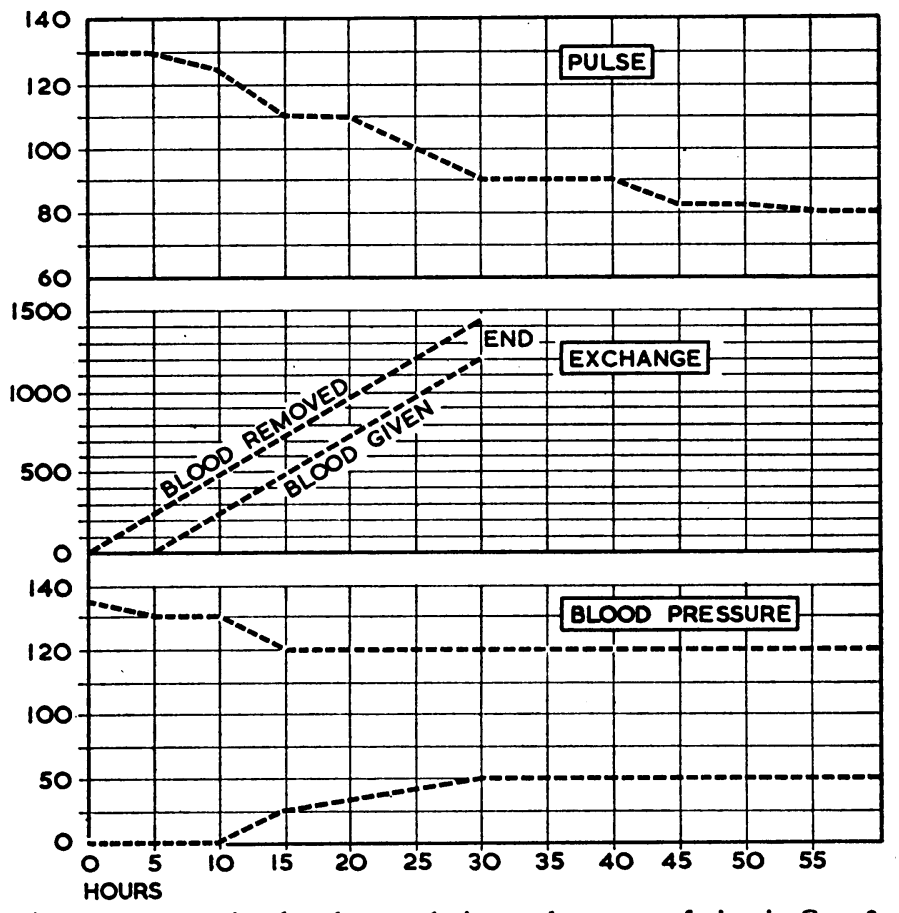

Blood-pressure and pulse changes during exchange transfusion in Case 2

\section{Clotting Mechanism}

No disturbance in the bleeding-time or clotting-time following transfusion in group A or group B was discovered on performing the aforementioned tests.

In group $A$ only two patients had platelet counts below $100,000 / \mathrm{cu}$. mm. on admission, but both counts increased to $100,000 / \mathrm{cu}$. mm. within 24 hours of exchange. In group B the platelet counts of two patients dropped below 100,000/ $\mathrm{cu} . \mathrm{mm}$. on the first and the second day respectively during daily packed-cell transfusions, but the counts exceeded 100,000/ $\mathrm{cu}$. $\mathrm{mm}$. by the third day. Significant lowering of the fibrinogen level never occurred in either group.

The Hess test was always negative and the prothrombin index never showed a significant lowering in any patient in the series. Both clinically and at operation a haemorrhagic diathesis was never evident in either group.

\section{Electrolyte Balance}

Electrolyte and $\mathrm{CO}_{2}$-combining-power studies were carried out in every case, as described previously, but the results obtained are far too numerous for presentation. An independent statistician to whom these results were submitted for 
analysis reported that the serial electrolyte and $\mathrm{CO}_{2}$ levels were within normal range and did not show any significant change in any case of either group.

\section{Citrate Toxicity}

Calcium studies were done as indicated above on all patients of the series. The results were all within normal limits and showed no significant change in any instance. There was likewise no clinical evidence of hypocalcaemia or citrate intoxication.

\section{Serum Bilirubin Changes}

In group $\mathrm{A}$ a rise of more than $1 \mathrm{mg} . / 100 \mathrm{ml}$. in the serum bilirubin was manifest within the first 24 hours of exchange transfusion in six patients; in one case (No. 30) the increase was from 1 to $3.2 \mathrm{mg}$. In group B the rise of more than $1 \mathrm{mg}$. in the serum bilirubin was seen within three days of packed-cell transfusion in four patients, the greatest rise being from 1.1 to $3.3 \mathrm{mg}$.

\section{Operative Delay}

For the purpose of this study our criterion of the patient's fitness for an emergency operation was that the haemoglobin level should be above $9.6 \mathrm{~g} . / 100 \mathrm{ml}$., without evidence of cardiac failure. Where possible, operation was delayed until these requirements were fulfilled.

In group A we were able to carry out necessary emergency operative procedures-for example, dilatation and curettage, forceps delivery, caesarean section, laparotomy for ectopic pregnancy, polypectomy, and haemorrhoidectomy-immediately after exchange transfusion. Likewise, five cases had an exchange transfusion during the first stage of labour, and so approached the second stage with a haemoglobin of $9.6 \mathrm{~g}$./ $100 \mathrm{ml} .(65 \%)$. In accordance with our practice other nonemergency procedures-for example, hysterectomy for uterine fibroids-were delayed for about 10 days after transfusion to permit the patient's vital organs to recover from possible illeffects of anaemia before operating.

In group B 12 patients required an operation. Seven required dilatation and curettage, and these procedures were delayed until the third day while the patients were being transf used.

Two patients with menorrhagia due to uterine fibroids were transfused slowly. One was in cardiac failure on admission, and it was possible to give a transfusion only by doing a medical venesection at the same time. Because of the time taken to correct the anaemia and coexisting pelvic infection, it was three weeks before she was ready for hysterectomy.

Case No. 24 was in cardiac failure with a haemoglobin of $4.4 \mathrm{~g} . / 100 \mathrm{ml}$., and though she was in urgent need of a laparotomy for an extrauterine pregnancy her general condition was too critical to permit operating until the lapse of three days on slow blood transfusion.

\section{Discussion}

The clinical results of this study provide proof that exchange transfusion is a safe and rapid method of increasing the haemoglobin in patients with severe anaemia. Striking indeed is the contrast of only 26 minutes required for exchange transfusion as opposed to three days required for conventional packed-cell infusion for correction of severe anaemia.

Exchange transfusion is of particular advantage to patients in cardiac failure. Thus all patients in group A were out of failure by the end of the procedure, by contrast with those in group $\mathrm{B}$ in failure, who needed no less than a minimum of 48 hours to come out of failure, and, moreover, three required medical venesection during this procedure. For patients requiring urgent surgery but in whom cardiac failure due to anaemia precluded operation the advantage of exchange transfusion was obvious.

In approaching this study we were somewhat apprehensive about possible disturbances in clotting mechanism, electrolyte balance, citrate toxicity, and serum bilirubin changes that might result from exchange transfusion. For instance, a general haemorrhagic tendency associated with massive blood transfusion had been reported by several authors. Hiashi and Kawamura (1962), for example, studied 2,903 patients receiving blood transfusion and found that the incidence of the complication rose steadily from $3 \%$ in those receiving less than 3 litres to $33 \%$ in those receiving more than 7 litres in 24 hours.

Furthermore, with an exchange transfusion, not only the theoretical fears of transfusing a large quantity of stored blood existed, but the synchronous deprivation of a similar quantity of the patient's own blood, containing factors which might be essential for the clotting mechanism, was also feared. In this extensive series, however, no disturbance in the clotting mechanism was detected.

A further source of concern lay in possible changes in the electrolyte balance, because it is known that bank blood stored in acid citrate dextrose solution has an increased sodium content corresponding to the sodium added to the sodium citrate and that the potassium content of the plasma rises because potassium diffuses out of the erythrocytes on storage. Thus Le Veen, Schatman, and Falk (1960) regarded a high potassium content in the stored blood reaching the heart during massive blood transfusions as the main lethal factor in 50 out of 157 cases of cardiac arrest. No disturbance of the electrolyte balance was evident in this series, however, presumably because the quantity of blood used did not come into the category of a massive transfusion.

Finally, the possibility of citrate toxicity was feared from the acid citrate dextrose solution contained in the stored blood (Stewart, 1962). Firstly, hypocalcaemia could develop through the citrate combining with all the ionized calcium in the donor blood and so prevent coagulation. The use of excess citrate will further remove calcium ions from the blood of the transfused patient, and such a deficiency of ionized calcium can potentiate the action upon the heart of the high potassium content often found in stored bank blood. Secondly, citrate intoxication might occur, in which there is vasoconstriction of the vessels in the lungs, with consequent increase in pulmonary arterial pressure and depression of myocardial contractility. Yet in this series no evidence of citrate toxicity was detected. In using packed cells for transfusion there is a relatively small amount of plasma and therefore of citrate. Though calcium was not used routinely in this series for research reasons, it would appear from the literature (Stewart, 1962) that it might be wiser to administer calcium-for example, calcium gluconate $1 \mathrm{~g}$. for every $500 \mathrm{ml}$. of blood transfused.

Slight elevation of the serum bilirubin was noted in patients of both groups.

\section{Indications for Exchange Transfusion}

From our experience of the cases we have presented we would recommend exchange transfusion as a valuable procedure in the following circumstances:

1. All cases of cardiac failure due to severe anaemia.

2. All cases of severe anaemia requiring urgent operationfor example, dilatation and curettage, polypectomy, laparotomy for ectopic pregnancy, and caesarean section. 
3. In pregnant patients with severe anaemia (whether irondeficiency or megaloblastic in type) who are near term. The potential hazards of post-partum haemorrhage or an operative procedure exists, as in every parturient.

In the haemolytic type of anaemia due to sickle-cell disease and malaria seen in Western Nigeria Fullerton and Turner (1962) have also shown the value of exchange transfusion.

\section{Summary}

A study is presented of the indications and effects of exchange transfusion in gynaecology and obstetrics.

The investigation includes a detailed study of 50 consecutive patients who on admission had a haemoglobin level below $4.4 \mathrm{~g}$./ $100 \mathrm{ml}$. (30\%). These patients were assigned by the method of random sampling to receive either an exchange transfusion or a slow packed-cell transfusion.

In no case was the cardiac function, clotting mechanism, or electrolyte balance in any way impaired, nor was there any evidence of citrate toxicity.
Subsequent exchange transfusion of a further 31 patients lends support to our finding that exchange transfusion is a safe procedure, the indications for which have been discussed. Thus exchange transfusion is of great value to the woman in anaemic cardiac failure, and to the severely anaemic patient who is pregnant, is approaching delivery, or requires an urgent gynaecological or obstetrical operation.

We are grateful to Professor J. Lawson, of University College Hospital, Ibadan, for valuable suggestions in the initial stages of this study, and to Dr. J. Powell, of the University of Natal, for assistance in the statistical analysis of our results. We also acknowledge with gratitude permission given by Dr. Nupen, Superintendent of King Edward VIII Hospital, Durban, to publish this work.

REFERENCES

Fullerton, W. T., and Turner, A. G. (1962). Lancet, 1, 75. Hiashi, H. and K̈awamura. K. (1962). Bibl. haemal. (Basel), 13, 480. Le Veen, H. H., Schatman, B., and Falk, G. (1960). Surgery, 47, 364 Philpott, R. H., Foster, N. E. G., and Crichton, D. (1963). Paper

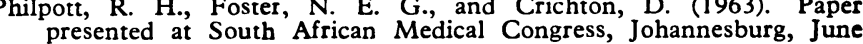
1963.

Stewart, J. W. (1962). In Modern Trends in Surgery, edited by W. T. Irvine. Butterworth, London.

\section{Preliminary Communications}

\section{Epsilon-aminocaproic Acid Therapy for Dental Extractions in Haemophiliacs}

\section{Brit. med. F., 1966, 2, 1633-1634}

Much has been written regarding local and systemic measures to prevent and arrest dental haemorrhage in haemophiliacs (Matheson, 1949 ; Wishart et al., 1957 ; Winstock and Ingram, 1961 ; McIntyre et al., 1964). The present generally accepted regimen involves frequent transfusions of fresh frozen plasma combined with the local use of dental splints to protect the sockets, which are packed with oxidized cellulose soaked in bovine thrombin. Antihaemophilic globulin concentrates of human, bovine, or porcine origin have also been used with considerable success (Macfarlane et al., 1954; Biggs et al., 1965).

Lucas et al. (1962) advocated the use of hypnosis, combined with extensive local measures, as a means of obtaining haemostasis without the need of replacement therapy. Reid et al. (1964) suggested that hypnosis possibly prevented a rise in fibrinolytic activity resulting from mental stress. It was argued that artificial reduction of the activity of the fibrinolytic system should produce a similar effect, and success was claimed in normalizing the thrombelastograph tracings of haemophilic blood in vitro by the addition of epsilon-aminocaproic acid (E.A.C.A.). A series of dental extractions on haemophiliacs with the use of systemic E.A.C.A. combined with extensive local measures was carried out, obviating the need for replacement therapy.

In view of this apparent success it was decided to repeat the experiment in the United Bristol Hospitals on haemophiliacs requiring dental extractions. It was felt that the effectiveness of E.A.C.A. had not been proved beyond doubt by the previous series, since the local measures were so extensive that these alone might well have been responsible for much of the haemostasis. Though at the outset exactly corresponding local measures were used in the series reported here, an attempt was made to reduce them progressively and to place increasing reliance on E.A.C.A.

Since E.A.C.A. has no corrective influence on the thromboplastin generation test, it seemed reasonable that any beneficial result of the therapy would be equally apparent in both classical haemophilia and Christmas disease ; the present series therefore includes male patients with both these conditions.

\section{MethoD}

When a patient who was known or thought to have haemophilia or Christmas disease presented for dental surgery, a definite diagnosis was first established on the basis of a personal and family history of bleeding and a clearly defined deficiency in the thromboplastin generation test. A full dental assessment was carried out and dental haemorrhage splints were constructed immediately before admission to hospital and held in readiness as a precautionary measure.

On the patient's admission a full medical examination was carried out to ensure that there was no contraindication to dental surgery, general anaesthesia, or the use of E.A.C.A. Each adult patient was given E.A.C.A. by mouth at the rate of 24 g./day in four or six divided doses, beginning 12 hours preoperatively. Children were given proportionally the same amount on a weight-ratio basis.

Planned dental extractions were performed under general anaesthesia, with progressively fewer local measures aiding haemostasis as the series proceeded.

Though all patients began E.A.C.A. therapy at a rate of $24 \mathrm{~g} . /$ day, this rate was raised if oozing occurred, and attempts were made to lower it if haemostasis was entirely satisfactory. The final adult dose varied between 16 and $36 \mathrm{~g}$./day, with an equivalent lower range for children. The E.A.C.A. therapy was maintained until 24 hours after the sutures had been removed, normally for a total period of six or seven days. The first patients in the series received all their E.A.C.A. by mouth in a syrup ; to the later patients it was given by mouth for 12 hours, then in a saline drip intravenously from a few hours preoperatively until about 24 hours postoperatively, after which it was again given by mouth. 